\title{
EXPERIÊNCIAS DE CONCILIAÇÃO: ANALISANDO AS RELAÇÕES DE GÉNERO DURANTE A ATUAL CRISE ECONÓMICA
}

\author{
Cláudia Múrias
}

Associação Espaços, Projetos Alternativos de Mulheres e Homens, Portugal

\section{Resumo}

Neste artigo, pretendemos analisar os papéis de género nas relações familiares entre mulheres e homens durante a atual crise económica, partindo dos discursos sobre práticas de conciliação de 22 pessoas, recolhidos através de 4 grupos de discussão focalizada, realizados em freguesias rurais de Viana do Castelo. Verificámos que as mulheres elaboram inúmeras estratégias para organizar o seu dia-a-dia, procurando conciliar a profissão com a vida familiar, sem contar com o apoio dos maridos, mesmo quando estes se encontram em situação de desemprego. Concluímos que a partilha das expectativas que atribuem às mulheres a responsabilidade pelo cuidado da família impossibilita a consciência da desigualdade de género e a sua reivindicação social.

Palavras-chave: papéis de género, relações de género, práticas de conciliação, organização familiar.

\section{Abstract}

Reconciliation experiences: analysing gender relations in the current economic crisis

In this paper, we analyse gender roles in family relations between women and men during the current economic crisis, using the discourses of reconciliation practices of 22 people, collected through four focus groups that were conducted in rural districts of Viana do Castelo. We found that women develop and employ several strategies to organise their daily routine, in order to reconcile professional and family life, without relying on their husbands' support, even when they are unemployed. We concluded that shared expectations that hold women alone responsible for family care preclude the awareness of gender inequality and its related social claim.

Keywords: gender roles, gender relations, reconciliation practices, family organisation.

\section{Resumé}

Les expériences de conciliation: analyse des relations entre les sexes dans le contexte actuel de crise économique

Dans cet article, nous analysons les rôles de genre dans les relations familiales entre les femmes et les hommes dans le contexte actuel de crise économique, en utilisant les témoignages de 22 personnes sur leurs pratiques de conciliation, recueillis lors de quatre groupes de discussion réalisés dans les districts ruraux de Viana do Castelo. Nous avons constaté que les femmes recourent à de nombreuses stratégies pour organiser leur quotidien, en essayant de concilier vie professionnelle et familiale, sans pouvoir compter sur le soutien de leurs maris, même quand ceux-ci sont au chômage. Nous en avons conclu que les attentes partagées social quant à la responsabilité des soins de la famille incombant aux femmes, empêche la prise de conscience de l'inégalité des sexes et leur revendication sociale.

Mots-clés: rôles de genre, relations entre les sexes, pratiques de conciliation, organisation de la famille. 


\section{Introdução}

Em Portugal, os estudos realizados sobre a organização familiar mostram de forma consistente que o ingresso em massa das mulheres no mundo profissional não se traduziu em alterações significativas nas práticas familiares ( $c f$. Amâncio, 2007; Perista, 1999; Poeschl e Serôdio, 1998; Poeschl, 2000; Wall, 2007; Wall, Aboim e Cunha, 2010).

Facto surpreendente se considerarmos, tal como refere Vírginia Ferreira (2010), que o investimento público que se seguiu ao 25 de Abril de 1974, se traduziu em iniciativas de apoio à manutenção de postos de trabalho, que evitaram a estagnação da economia, promoveram a expansão do consumo e permitiram o aumento do emprego feminino. Efetivamente, as políticas públicas delineadas então, como a fixação do salário mínimo, do subsídio de desemprego, da licença de maternidade de 90 dias e de outros direitos na gravidez, maternidade e de assistência à família sem perda de regalias ou remuneração (p.e. dispensa de trabalho para idas às consultas médicas de controle de gravidez, dispensa de 2 horas para amamentação; faltas até 30 dias para assistência em caso de doença; dispensa ou opção de trabalho a trabalho parcial para acompanhemento de crianças menores de 12 anos), possibilitaram a inserção das mulheres no mercado de trabalho, tornando-a economicamente atrativa (Ferreira, 2010; Rodrigues, 1995).

Também a renovação legislativa levada a cabo pelo Estado, entre meados da década de 1970 e meados da década de 1980, com a elaboração de políticas públicas de combate à discriminação social, económica, cultural e política das mulheres, permitiu operar uma verdadeira reforma progressista, nomeadamente, permitiu a instalação e a institucionalização dos mecanismos nacionais para a igualdade (Monteiro, 2010). No entanto, socialmente «estas políticas foram recebidas como uma inevitabilidade decorrente do próprio processo de modernização e de democratização do país» (Ferreira, 2010: 25), sem grande questionamento, compromisso ou apoio social aos direitos das mulheres. Mesmo a intervenção estatal acabou por aproveitar o ímpeto revolucionário e ir a reboque das comunidades que se organizaram em movimentos de autogestão, nomeadamente relativamente às reivindicações relacionadas com a implementação de uma educação pré-escolar e infantil, tendo o poder local sido obrigado a contribuir no apoio técnico e financeiro às iniciativas populares de proliferação de creches e infantários - ainda que este apoio tenha ficado muito aquém das necessidades reais da população (Bairrão e Vasconcelos, 1997).

Desta forma, é de destacar a alta taxa de atividade feminina no grupo etário dos 25 aos 49 anos que Portugal apresentava em 1993, 75,1\%, a terceira taxa de atividade feminina mais alta da Europa, a seguir à Holanda, que atingiu os $90 \%$ e à França que registou 77\%. Este dado é significativo devido à reduzida expressão das mulheres casadas e empregadas que trabalhavam a tempo parcial em Portugal, apenas 8,3\%, contrariamente à Holanda em que tal acontecia com $80 \%$ delas (Eurostat cit in Ferreira, 1998). 
Ao analisar os resultados do Inquérito à Ocupação do Tempo realizado pelo Instituto Nacional de Estatística (INE, 2001) no final da década de 1990 - mais especificamente em 1999, nomeadamente ao uso do tempo das pessoas empregadas, Heloísa Perista (2002) refere haver uma profunda assimetria na participação dos homens e das mulheres no trabalho não pago: os homens gastavam, em média, $9 \mathrm{~h} 11 \mathrm{~m}$ na atividade profissional e $1 \mathrm{~h} 38 \mathrm{~m}$ no trabalho não pago, enquanto as mulheres gastavam, em média, $8 \mathrm{~h} 04 \mathrm{~m}$ no trabalho pago e $4 \mathrm{~h} 07 \mathrm{~m}$ no trabalho não pago.

Desta forma, no virar do século XX para o século XXI, em Portugal, as mulheres trabalhavam aproximadamente mais duas horas e meia por dia em tarefas domésticas e prestação de cuidados à família, sendo responsáveis por preparar as refeições, limpar regularmente a casa, fazer as compras habituais ou cuidar da roupa, tarefas tipicamente femininas, que consomem mais tempo e precisam de ser realizadas com uma maior regularidade do que as tarefas realizadas pelos homens ou tipicamente masculinas, como reparar objetos, cuidar da jardinagem, do carro, dos serviços administrativos ou das compras esporádicas (Poeschl, Múrias, Costa e Silva, 2001/2). Quando tinham crianças pequenas, as mulheres continuavam a executar mais de metade das tarefas parentais, encarregando-se quer das tarefas relacionadas com a higiene e a alimentação, quer do trabalho emocional e relacional necessário à manutenção das redes informais de entreajuda interfamiliar (cf. Perista, 2002; Poeschl, 2010). Sendo ainda as principais responsáveis pelo apoio intergeracional, através da ajuda doméstica e financeira, da guarda das crianças e dos cuidados gerais em caso de doença e incapacidade (Fernandes, 2001), as mulheres continuavam a corporizar a sociedade-providência, sobrecarregando-se.

Boaventura Sousa Santos $(1995 ; 1994)$ já tinha salientado que, para além do altruísmo, da solidariedade e da reciprocidade, a sociedade-providência, constitutiva de uma forma específica de sociabilidade moderna, transportava em si a ausência de direitos, a discriminação sexual das mulheres (ancorada no patriarcado) e o paternalismo nas relações sociais. Esta forma de sociabilidade moderna em Portugal era explicada por um modelo de sociedade ainda com forte presença da pequena agricultura familiar e uma elevada percentagem de população pluriativa a viver em meio rural, cuja mobilidade tinha combinado o salto da emigração com a fixação territorial associada a um processo de industrialização antigo e multipolar, que permitiu ao Estado português permanecer autoritário e distante, enquanto possibilitava a informalidade providencial das relações sociais (Santos, 1994; 1993).

Por sua vez, Sílvia Portugal (2008) ressaltava a crença familialista - que consiste na ideia de que a família tem capacidade intrínseca de resolução dos seus próprios problemas privados - como responsável pelo fraco investimento público no apoio à família existente em Portugal e pela pouca relevância de medidas promotoras da conciliação ou apoio social ao desemprego. Para esta autora, as obrigações familiares, que transcendem a família nuclear e recaem sobre a parentela, 
justificam a posição não intervencionista por parte do Estado em várias situações de risco social (doença, deficiência, desemprego, etc.) que é assumido como responsabilidade da família e das redes de parentesco.

Assim, a informalidade das relações sociais em Portugal não permitiu que o contrato social de género, ou seja, as relações de poder entre mulheres e homens, fosse questionado ou negociado no sentido da igualdade plena. Se o declínio do modelo social do homem ganha-pão versus mulher doméstica e mãe de família é indubitável (cf. Wall, 2007; Wall, Aboim e Cunha, 2010), muitas continuidades e descontinuidades têm emergido e permanecido nestas relações de poder, contribuindo para manter a assimetria simbólica (Amâncio, 1994), ou seja, as valorizações desiguais de mulheres e de homens, bem como dos papéis, funções ou tarefas femininas e masculinas. Algumas prendem-se com as desigualdades estruturais do emprego oferecido e/ou ocupado pelas mulheres, mais precário, desqualificado e mal pago, relativamente ao emprego oferecido e/ou ocupado pelos homens ( $c f$. Casaca, 2010; Wall, Aboim e Cunha, 2010). Desta forma, as desigualdades dos usos do tempo entre mulheres e homens têm-se mantido constantes ao longo dos últimos anos: segundo dados do $4^{\circ}$ Inquérito Europeu às Condições de Trabalho, realizado em 2005 pela Fundação Europeia para a Melhoria das Condições de Vida e de Trabalho (Eurofound cit in CITE, 2012), as mulheres portuguesas despendiam semanalmente mais 16 horas do que os homens na realização de trabalho não pago, o que perfaz aproximadamente duas horas e meia por dia, já anteriormente encontradas por Perista (2002).

Se a manutenção das desigualdade entre mulheres e homens na familia é incontestável (cf. Perista, 2002; Wall, Aboim e Cunha, 2010), as explicações para tal também não parecem divergir. Diane Wille (1995) avaliou as interações de pais e mães com bebés até aos 6 meses, e perante as inseguranças que os homens demostraram sobre as suas competências parentais, defendeu que a sociedade deveria encorajar os homens a assumir a parentalidade e cuidarem das crianças. De facto, a investigação desenvolvida sobre os estereótipos de género tem confirmado a existência de um vasto consenso acerca dos atributos associados a homens e mulheres, sendo atribuídos aos homens atributos instrumentais e/ou agênticos e às mulheres atributos expressivos e/ou comunais (cf. Poeschl, Múrias e Ribeiro, 2003). Também Gerold Mikula (1998) justificou as iniquidades de participação entre homens e mulheres nas tarefas domésticas pelo facto de corresponderem às normas dominantes na sociedade. Gabrielle Poeschl (2010), nos seus estudos sobre os papéis sociais de género, encontrou também um reforço das normas sociais dominantes, através de uma maior reprovação dos homens quando não são os principais provedores da família, e uma maior reprovação das mulheres quando não assumem a responsabilidade pelo cuidado da família. Assim o padrão familiar de dupla carreira ou de duplo trabalho encontrado por Chiara Saraceno (1992), em que as mulheres reorganizam mais facilmente as suas prioridades para virem ao encontro das exigências de tempo provenientes da família, enquanto os homens tendem a privilegiar as exigências de tempo prove- 
nientes do trabalho, parece corresponder às expectativas socialmente partilhadas sobre os papéis de género. Os estereótipos e papéis de género lançam as sementes que favorecem a legitimação das desigualdades entre mulheres e homens em aspetos tão vitais como o acesso ao emprego e a cargos de chefia, as diferenças retributivas, a diferente assunção de responsabilidades familiares e domésticas. Se a partilha das tarefas for vista como uma ajuda, uma dádiva, um favor do homem à mulher, pode limitar seriamente a capacidade de negociação das mulheres para obterem uma partilha igualitária (Vandelac, 1983).

Por outro lado, Ursula Müller (1998) tem salientado a conflitualidade existente nas relações de género, afirmando que as mulheres infantilizam os homens em casa enquanto resposta ao assédio e aos comportamentos sexistas de que são alvo em público. No entanto, com estes comportamentos apenas contribuem para a manutenção das práticas familiares tradicionais. Poeschl et al. (2006) sugerem ainda que as mulheres podem estar motivadas para manter as práticas familiares tradicionais porque estas práticas criam a ilusão de que os homens dependem delas, e a eventual dependência dos homens cria a ilusão de que as mulheres têm poder, não só dentro da família, como também na sociedade (cf. Poeschl, Pinto, Múrias, Silva e Ribeiro, 2006). Portugal (2008: 27) refere que «à medida que se esbatem as diferenças sexuais no mercado de trabalho e que se dilui o modelo do provedor masculino, as justificações para as desigualdades nos cuidados dos filhos tornam-se cada vez mais essencialistas».

Contudo, a repartição desigual do trabalho familiar tem consequências nefastas para as mulheres: enfraquece a posição das mulheres nas relações conjugais, mantém os homens afastados da vida familiar, permite manter a assimetria entre homens e mulheres no mercado de trabalho e coloca sobre as mulheres pressões constantes de subcarga e mal-estar (Múrias e Ribeiro, 2012).

Se a globalização da economia tinha ampliado a discriminação das mulheres (cf. Santos, 1995), o atual contexto de crise económica poderá ser uma agravante na fragilização da sua posição social. Em tempo marcado pela austeridade e pela retração da despesa pública em proteção social e no apoio ao crescimento económico (Ferreira e Monteiro, 2013), torna-se pertinente perceber os impactos que a desregulamentação do mercado de trabalho, extremamente exigente e assente numa lógica de presentismo ${ }^{1}$ (Monteiro, 2014), terá sobre a vida das pessoas, mulheres e homens, nomeadamente sobre a conciliação trabalho-família.

Estatísticas obtidas já em contexto de crise revelam que os homens renunciam mais ao tempo livre para responderem a situações profissionais, com $12 \%$ a fazê-lo uma ou mais vezes por semana, comparativamente com 8,1\% das mulheres, enquanto as mulheres sentem mais dificuldade $(24,2 \%)$ em tirar uma ou duas horas durante o horário de trabalho para tratar de assuntos pessoais ou familiares, comparativamente com 17,9\% de homens (CITE, 2014). Estas dinâmicas fra-

Entende-se por presentismo a situação em que a pessoa comparece no emprego, embora incapacitada para desempenhar com eficácia as suas funções ou trabalho 
gilizam as mulheres relativamente ao emprego, nomeadamente numa altura em que a economia se encontra em regressão: em 2011, a taxa de emprego masculino era de $73,4 \%$ e a taxa de emprego feminino era de $64,8 \%$; em 2013, a taxa de emprego masculino passou para $68,8 \%$ e a taxa de emprego feminino para $62,4 \%$. Por sua vez, a taxa de desemprego subiu de 15,5\%, em 2012, para 16,2\%, em 2013, sendo de 16,0\% para os homens e de 16,4\% para as mulheres. Embora o acréscimo global da taxa de desemprego em 2013 (+0,7 p.p.) tenha tido reflexos em ambos os sexos, foi mais acentuado na taxa das mulheres $(+0,9$ p.p.) do que na dos homens (+0,4 p.p.) (CITE, 2014).

Relativamente a Viana do Castelo, segundo dados dos Censos, em 2011, a taxa de emprego masculino era de $53,9 \%$ e a taxa de emprego feminino era de $42,4 \%$, constatando-se a existência de 2343 homens em situação de desemprego face a 2839 mulheres na mesma situação (Pordata, 2015). Segundo o Instituto de Emprego e Formação Profissional, estes dados aumentaram em 2012, sendo 2513 homens em situação de desemprego face a 2990 mulheres na mesma situação (IEFP, 2015).

No intuito de analisar (e transformar) as relações de género nas freguesias rurais de Viana do Castelo, a Associação Juvenil de Deão promoveu o projeto de intervenção comunitária Caminhos de Igualdade ${ }^{2}$, entre julho de 2011 e janeiro de 2014, que possibilitou a problematização das condições de vida atuais decorrentes da crise económica, através da tomada da palavra pela comunidade local (cf. Múrias e Freire, 2014).

Neste artigo, apresentaremos apenas o trabalho realizado numa das atividades, os grupos de discussão focalizada. Organizados com pessoas em idade ativa para identificar representações e práticas sociais, os grupos de discussão focalizada permitiram que as pessoas conversassem sobre a conciliação entre esferas de vida para, num segundo momento e partindo dos discursos elaborados, serem dinamizadas com a mesma população, oficinas do poder que possibilitassem trabalhar a participação igualitária de mulheres e homens na vida pública (esfera laboral) e na vida privada (esfera familiar), implicando assim, a capacitação e o empoderamento das mulheres no mercado de trabalho, bem como a capacitação e o empoderamento dos homens na família (cf. Múrias e Freire, 2013; Múrias e Freire, 2014).

\section{Grupos de discussão focalizada}

Os grupos de discussão consistiram em momentos de partilha exploratórios da temática da conciliação entre esferas de vida. Contaram com a presença de

2 Projeto financiado pela Comissão para a Cidadania e Igualdade de Género (CIG), ao abrigo do Eixo 7 - Igualdade de Género, Tipologia de Intervenção 7.3 - Apoio Técnico e Financeiro às ONG (058620/2011/73) do Programa Operacional Potencial Humano (POPH) do Quadro de Referência Estratégico Nacional (QREN) e do Fundo Social Europeu (FSE). 
uma moderadora que levantou um conjunto de questões acerca das dimensões do quotidiano de cada pessoa (esfera de vida profissional ou laboral; esfera de vida doméstica; esfera de vida familiar ou parental; esfera de vida social, cívica ou voluntariado; esfera de vida de lazer ou pessoal) e tiveram uma pessoa observadora, para apontar as questões não audíveis.

Foram organizados quatro grupos, de acordo com duas categorias sociais de pertença: a pertença sexual das pessoas - rapazes ou homens versus raparigas ou mulheres; e a relação com o trabalho - exercer uma profissão versus inatividade, no intuito de verificar se a pertença a diferentes grupos se traduzia em formas de pensar ou práticas comportamentais específicas. Participaram 22 pessoas (11 mulheres, 11 homens). Relativamente à organização familiar, coexistiram três tipos de agregado familiar: agregados de dupla carreira ou duplo trabalho, agregados tradicionais (mulher doméstica cuidadora da família, homem ganha pão) e agregados unipessoais.

Um dos grupos de discussão focalizada foi constituído por 7 mulheres profissionalmente ativas -4 inseridas em agregados de dupla carreira/duplo trabalho, 2 inseridas em agregados unipessoais e 1 inserida num agregado tradicional. Outro grupo de discussão foi constituído por 6 homens profissionalmente ativos - 4 inseridos em agregados de dupla carreira/duplo trabalho e 2 inseridos em agregados unipessoais. Um terceiro grupo de discussão foi constituído por 4 mulheres profissionalmente inativas - 2 estudantes e 1 desempregada inseridas em agregados de dupla carreira/duplo trabalho e 1 doméstica inserida num agregado tradicional. $\mathrm{O}$ restante grupo de discussão foi constituído por 5 homens profissionalmente inativos - 3 estudantes inseridos em agregados de dupla carreira/duplo trabalho e 2 desempregados inseridos em agregados tradicionais.

As conversas ocorridas nos grupos de discussão focalizada foram transcritas e analisadas, de acordo com as categorias dedutivas: dimensões da conciliação e categorias sociais dos/as participantes, possibilitando o surgimento indutivo de problemáticas de conciliação entre esferas de vida em contexto rural (cf. Múrias e Freire, 2013; Múrias e Freire, 2014). Estas problemáticas permitiram a construção de histórias-desafio que foram trabalhadas nas oficinas de poder.

As oficinas de poder foram idealizadas enquanto instrumento de facilitação da compreensão das problemáticas, que promovesse a aquisição de informação e o debate, para melhor elaborar propostas concretas que garantissem condições de igualdade de participação e de empoderamento das pessoas, nomeadamente no sentido da igualdade de oportunidades entre mulheres e homens. O início dos trabalhos assentou na visualização e experimentação criativas das soluções apontadas nos grupos de discussão focalizada, tendo funcionado as histórias-desafio como um exemplar criativo, que criou condições para a reflexão coletiva, crescente consciencialização e procura de resolução para as problemáticas de conciliação apontadas.

De seguida, apresentamos as problemáticas de conciliação mais relevantes para este grupo de participantes. 


\section{As problemáticas de conciliação em espaço rural em tempos de crise}

1. Os estereótipos de género e a desigual participação das mulheres nas tarefas domésticas e familiares: a sobrecarga da dupla tarefa

A desigualdade de participação nas tarefas domésticas e familiares e a sobrecarga de trabalho evidenciaram-se enquanto obstáculo à participação das mulheres no mercado de trabalho. As mulheres elaboram inúmeras estratégias para organizar o seu dia-a-dia, dentro de uma perspetiva de conciliação trabalho-família, com a ativação das redes informais de entreajuda intergeracional, sem contar com o apoio dos companheiros, mesmo quando têm agregados de dupla carreira ou duplo trabalho:

A minha mãe agora trabalha na fábrica, mas antes trabalhava no comércio e o horário do comércio é muito maior. É das 9 da manhã... bem a função dela era das 7h30m da manhã às 7h30m da noite. Tinha a hora de almoço. Então, tentava conjugar com a nossa hora de almoço com a dela para ter um bocado de tempo para estar connosco. À noite, lembro-me que era pequena e ela chegava a casa, muitas vezes às 9 da noite. Chegávamos a casa, jantávamos para lá qualquer coisa rápida e era «vamos jogar num instante aqui às escondidinhas» (...) Depois, pegava, deitava-nos e ficava a passar a ferro, a dobrar e a preparar as coisas p' ró dia seguinte, porque às 6 da manhã, já estávamos a pé novamente (solteira, estudante).

Mesmo assim eu vejo pela minha mãe, é ela que tem o cuidado. A minha avó paterna mora ao nosso lado e vejo que se não for a minha mãe, o meu pai passa ao lado. Muitas vezes, nem se lembra. É a minha mãe que tem aqueles cuidados de quer ir ao médico, precisa disto, quer ir aquilo... nota-se mais isso. São raros os homens que são despachados e que se desenrascam (solteira, estudante).

Ai, se estou à espera dele para me dar de comer, fazer comidinha? Nem pensar! Nessa parte não tenho sorte (casada, empregada fabril).

Apesar destas mulheres despenderem mais tempo com a realização das tarefas domésticas, muitas justificaram o facto de os homens não se sentirem responsáveis pela realização do trabalho doméstico - e não o realizarem - culpabilizando-se ou culpabilizando outras mulheres, ou seja, através da culpabilização da cultura familiar. A salientar ainda o contraste entre a motivação das mulheres casadas para a manutenção das práticas tradicionais e a procura das mulheres solteiras pelo ideal de partilha igualitária nas práticas futuras:

Tenho um trabalho abrigado e ainda vou de carro. Ele vai para trabalhar no meio da lama e ainda vai de mota à chuva. E depois, também fico a pensar «ainda lhe vou deixar isso tudo?» Também chega a casa cheio de frio, todo molhado e ainda vai continuar lá fora a fazer essas coisas? Não! (casada, empregada de hipermercado). 
Eu, por acaso, não [partilho]. Porque o meu marido é músico e anda sempre fora. Não tem tempo para nada. Não dá mesmo! (casada, desempregada).

É uma questão de hábito... Também tem a ver com a educação que vem de trás (solteira, estudante).

Exacto! Porque é que o meu pai e os meus tios não sabiam fazer nada? Porque a minha avó não ensinou. E do outro lado, já sabiam tudo (solteira, profissional liberal).

Da nossa geração, é culpa das mães. Têm os meninos, «Ai, os meninos não podem!» A culpa é das mães da nossa geração. "Ah, é um menino», "porque é rapaz e porque num sei quê»... (solteira, estudante).

2. Os homens, os privilégios e os papéis de género: o retorno à divisão sexual do trabalho

Os homens manifestaram um grande grau de conservadorismo, legitimando os estereótipos e a reprodução da divisão tradicional de papéis de género, afastando qualquer eventualidade de partilha das tarefas femininas, atribuindo as responsabilidades domésticas regulares, que demoram mais tempo para a sua realização às mulheres e assumindo apenas as tarefas tipicamente masculinas, como a jardinagem, tarefa realizada com pouca regularidade:

Já está incutido em nós. Saber que a mulher, tipo ao sábado de manhã, faz a limpeza geral da casa. Acho que se ela não limpa... Não vai ser tão fácil desbloquear isso. A mulher ficar na cama e eu ir fazer a limpeza sozinho (solteiro, militar).

Convém que continuem assim! Tudo bem. Nós também temos outras coisas que elas não fazem. Nós temos que fazer, não é? Também é uma verdade! Podem dispor mais tempo para a limpeza e o homem dispor mais tempo para o jardim, etc. A minha esposa nunca cortou a relva! Tenho quase a certeza, não é? (casado, comerciante).

Mesmo quando a atual crise económica provoca situações de desemprego junto dos homens destes agregados, não se perspetiva a mudança. Pelo contrário, há um reforço da divisão sexual do trabalho. Há como que um evitar de qualquer ponto de aproximação a um processo de negociação que possa permitir a reformulação dos papéis tradicionais de género ou uma partilha democrática ou igualitária das tarefas:

Eu acho que se devia manter. $\mathrm{O}$ homem que traga o dinheirinho para casa e a mulher escusa de trabalhar. A minha mulher nunca trabalhou. A minha mulher era mantida por mim, nunca trabalhou. Ela fazia o trabalho de casa e eu fazia o trabalho fora de portas. E todos fossem assim, já era uma grande coisa (casado, desempregado). 


\section{Crise, direitos e produtividade: onde ficam os cuidados às crianças?}

De destacar que as expectativas que atribuem às mulheres a responsabilidade de cuidar das crianças acabam por constituir um obstáculo significativo à igualdade, uma vez que, para estes homens e mulheres, a conciliação da vida familiar com a vida profissional é um assunto de mulheres. Por sua vez, as políticas públicas e os direitos na gravidez, de maternidade ou de assistência à família, são concetualizados enquanto benefícios privados, negociáveis entre as mulheres e o patrão, bem ao encontro da crença familialista:

Vou partilhar a dificuldade de muitas trabalhadoras: lidar com o trabalho, lidar com os filhos e depois ir à escola, estar junto dos filhos... não dá! Os patrões não vão dar dias, isso é perda de produtividade. Não conseguem ir à escola, não conseguem acompanhar os filhos (casado, empregado fabril).

Quanto menos faltar, melhor! Tenho que ir, tenho que faltar «Ah não! Porque não mandas a avó com ele?» (casada, empregada fabril).

Eu fui trabalhar antes de terminar o tempo [licença de maternidade], mas foi por minha opção. Eu nunca tive esse problema. Mas lá está, um patrão também tem que ser para nós, e nós temos que ser para o patrão (casada, empregada fabril).

Eu conheço situações em que as mães começam a ser pressionadas durante a gravidez. Vão-lhes fazendo perguntas... «quanto tempo é que vais tirar?»,» se vais tirar o tempo máximo?» (...) E muitas são despedidas. Outras não são despedidas, sofrem pressão psicológica, que é muito pior e acabam elas por se demitir do cargo. Muitas vezes, chegam ao local de trabalho e não têm a tarefa que tinham, são destituídas (solteira, auxiliar de educação).

A crise surge nas palavras das participantes, com a descrição das recentes alterações às condições de trabalho. Num contexto de intensificação dos ritmos de trabalho, flexibilização dos horários, acentuada imprevisibilidade e desregulação das circunstâncias de trabalho, a conciliação das esferas de vida é um desafio constante, repleto de incertezas, angústias, pressões, desmotivações e contradições entre expectativas, normas, práticas, direitos e capacidades para os exercer:

Na instituição na qual eu trabalho, temos creche e temos prolongamento de jardim de infância e tenho notado (...) que os pais cada vez mais nos propõem o alargamento de horário. Nós abrimos às $7.30 \mathrm{~h}$ da manhã e fechamos às 19 horas (...) muitos com frequência telefonam «hoje vamos chegar atrasados», principalmente as mães, "porque tivemos uma reunião de urgência, por isto, por aquilo, porque agora temos que estar até mais tarde no trabalho (solteira, auxiliar de educação).

Eu trabalho por conta própria, estabeleço o meu próprio horário. Só que há uns anos atrás, as pessoas, os clientes ligavam para marcar uma consulta ou para tratar de 
determinados assuntos e nós, à partida, tínhamos a liberdade de dizer ou era da parte da manhã ou da parte da tarde, a esta hora, àquela... Agora não. Agora, cada vez mais, temos que nos cingir ao horário das pessoas, ou seja, antigamente as pessoas saíam do trabalho a umas horas para ir ao advogado, para ir ao médico, para ir tratar de determinados assuntos. Agora isso não acontece (...) Eu cada vez saio mais tarde do escritório, eu há dias que saio do escritório às 21 horas. Porquê? Porque as pessoas só depois do trabalho, às 18 horas, é que têm disponibilidade para lá ir (...) Agora por causa da falta da produtividade não se facilita coisíssima nenhuma (solteira, profissional liberal).

\section{Em jeito de reflexão...}

O princípio de igualdade, basilar nas sociedades democráticas atuais, sustenta-se na ideia de que todas as pessoas estão em igual posição perante as condições de acesso aos direitos fundamentais: políticos, cívicos, sociais, económicos e culturais. No entanto, estas mesmas sociedades têm, no seu seio, um conjunto de fundamentos e justificações para a existência de uma diferenciação entre as pessoas, sendo o sexo, a classe social, a situação económica, a instrução, a raça ou a etnia, a idade a que os indivíduos pertencem, fatores que condicionam os modos de vida das pessoas, as suas práticas, as suas ambições e as suas necessidades. Desta forma, a luta pelos direitos fundamentais faz-se através da consciencialização sobre o nosso posicionamento na história, experiência e visão de mundo individual e de grupo, requerendo dimensões de reconhecimento e de possibilidade de asserção da voz pessoal, que permita a participação cívica implicada e a reivindicação social. Para tal, torna-se pertinente desenvolver a capacidade de literacia, ou seja a capacidade de leitura do mundo e de intervenção ou ação na polis, segundo inspiração de Paulo Freire (Macedo, Vasconcelos, Lacerda e Vaz Pinto, 2001).

Nos grupos de discussão focalizada, ao problematizar-se a conciliação entre as esferas de vida, possibilitou-se a emergência acerca de formas de pensar e agir comuns: os estereótipos e papéis de género dominantes. Verificou-se assim, que nas freguesias rurais de Viana do Castelo, os estereótipos e papéis de género de maternidade e domesticidade acabam por constituir um obstáculo significativo a uma negociação entre mulheres e homens que permita a construção de um contrato social de género mais igualitário na região, mantendo assim as condições sociais e simbólicas que reproduzem a assimetria entre homens e mulheres na família e no mercado de trabalho (Múrias e Ribeiro, 2012).

Efetivamente, o 25 de Abril de 1974 trouxe a Portugal a institucionalização da igualdade entre mulheres e homens, criando novas lógicas relacionais e possibilitando a gradual escolarização de toda a população, sobretudo as mulheres, o que se traduziu em novas oportunidades de emprego, novas práticas profissionais, com a entrada massiva das mulheres no mercado de trabalho e o rápido crescimento do emprego no setor dos serviços, fenómenos unanimemente apontados 
como os que mais têm determinado as recomposições sociais verificadas ao longo das últimas décadas em Portugal (Ferreira, 1998). Porém, o ingresso massivo das mulheres no mundo profissional não se traduziu em alterações significativas nas práticas familiares, apesar de atualmente haver maior expectativa para os homens cuidarem das crianças (cf. Wall, Aboim e Cunha, 2010), em Portugal, a sociedade em geral e a comunidade local não os encoraja nem os prepara para dar prioridade ao seu papel parental. Como resultado, nas freguesias rurais de Viana do Castelo, os estereótipos e papéis de género ainda condicionam uma maior participação das mulheres nas tarefas domésticas e parentais, uma vez que as mulheres continuam a organizar mais facilmente as suas prioridades para virem ao encontro das exigências de tempo provenientes da família, enquanto os homens tendem a privilegiar as exigências de tempo provenientes do trabalho, recusando-se à participação nas vastas e exigentes tarefas domésticas femininas. Talvez só a prolongada ausência física da mulher de casa por motivos de trabalho, tal como refere Müller (1998), possa operar uma transformação nestes homens, permitindo a passagem da condição de recebedor à de prestador de cuidados, uma vez que a situação de desemprego não fez alterar a repartição sexual das tarefas familiares. Por outro lado, as mulheres casadas, com as suas justificações e culpabilizações, parecem estar motivadas para a manutenção das práticas tradicionais (Mikula, 1998; Müller, 1998; Poeschl, Pinto, Múrias, Silva e Ribeiro, 2006), assumindo a manutenção da sociedade-providência (Santos, 1994).

A atual crise económica - marcada pela austeridade e pela retração da despesa pública em proteção social e no apoio ao crescimento económico - possibilitou a aceleração da desregulamentação do mercado de trabalho, cada vez mais exigente, que dificulta ainda mais a conciliação entre esferas de vida, sendo fator de tensões e contradições entre expectativas, normas, práticas, direitos e capacidades para os exercer (Monteiro, 2014; Monteiro e Portugal, 2013). Neste sentido, não é surpreendente que as empresas portuguesas tenham aderido a práticas de intimidação, assédio e outras violências para reforçar a lógica de presentismo na cultura organizacional, com base na representação ideal de trabalhador neutro (Acker, 2009) e descurando as suas responsabilidades sociais, ao agravar os constrangimentos à conciliação trabalho-família. Mais uma vez, a crença familialista (Portugal, 2008) permite a ilusão de que os problemas organizacionais não vão a par com os problemas privados de cada trabalhadora, permitindo que as mulheres trabalhadoras portuguesas revelem níveis de satisfação com a relação trabalho-família inferiores às das suas congéneres da Bulgária, da Finlândia, da Suécia, da Holanda, da Alemanha, da Hungria (Rodrigues, Barroso e Caetano, 2010).

A crise económica agrava a posição social das mulheres, uma vez que permite acentuar as desigualdades existentes. Perante a precarização e flexibilização do emprego, há o risco de as mulheres não conseguirem fazer uma gestão da vida profissional que as proteja do subemprego, desemprego ou mesmo da exclusão do mercado de trabalho (Casaca, 2010), impossibilitando-as de viverem de acordo com os padrões de vida dominante, ou seja, condicionando-as para 
situações de pobreza relativa próprias das sociedades desenvolvidas (Pereirinha, 2008).

Assim, entendemos que as expectativas que atribuem às mulheres a responsabilidade de cuidar das crianças acabam por constituir um obstáculo significativo à participação igualitária entre homens e mulheres, mantendo as assimetrias de género na família e no mercado de trabalho, e em consequência, contribuindo para a feminização da pobreza (Pierce, 1978 cit in Pereirinha, 2008) e para a não reivindicação social da igualdade de género.

\section{Referências}

Acker, Joan (2009), «From glass ceiling to inequality regimes», Sociologie du Travail 51(2), 199-217.

Amâncio, Lígia (2007), «Género e divisão do trabalho doméstico - O caso português em perspectiva», in Karin Wall; Lígia Amâncio (Orgs.), Familia e género em Portugal e na Europa, Lisboa, Instituto de Ciências Sociais, 181-211.

Amâncio, Lígia (1994), Masculino e feminino: A construção social da diferença, Porto, Edições Afrontamento.

Bairrão, Joaquim; Vasconcelos, Teresa (1997), «A educação pré-escolar em Portugal: contributos para uma perspectiva histórica", Inovação: revista do Instituto de Inovação Educacional 10(1), 7-19.

Casaca, Sara Falcão (2010), "A (des)igualdade de género e a precarização do emprego", in Virgínia Ferreira (Orgs.), A Igualdade de Mulheres e Homens no Trabalho e no Emprego em Portugal: Políticas e Circunstâncias, Lisboa, Comissão para a Igualdade no Trabalho e Emprego, 261-291.

CITE (2014), Relatório sobre o Progresso da Igualdade entre Mulheres e Homens no Trabalho, no Emprego e na Formação Profissional - 2013, Lisboa, Comissão para a Igualdade no Trabalho e no Emprego.

CITE (2012), Situação das Mulheres e dos Homens no Mercado de Trabalho, 2011, Lisboa, Comissão para a Igualdade no Trabalho e no Emprego.

Fernandes, Ana (2001), «Velhice, solidariedades familiares e política social: Itinerário de pesquisa em torno do aumento da esperança de vida», Sociologia, Problemas e Práticas 36, 39-52.

Ferreira, Virgínia (1998), Mulheres em Portugal: situação e paradoxos, Oficina do CES, 119.

Ferreira, Virgínia (2010), «Introdução», in Virgínia Ferreira (Orgs.), A Igualdade de Mulheres e Homens no Trabalho e no Emprego em Portugal: Políticas e Circunstâncias, Lisboa, Comissão para a Igualdade no Trabalho e Emprego, 23-29.

Ferreira, Virgínia; Monteiro, Rosa (2013), Trabalho, Igualdade e Diálogo Social - Estratégias e desafios de um percurso, Lisboa, Comissão para a Igualdade no Trabalho e Emprego.

Instituto do Emprego e Formação Profissional (2015), «Concelhos: Estatísticas mensais» [em linha] disponível em https://www.iefp.pt/en/estatisticas [consultado em 02/09/2015].

Instituto Nacional de Estatística (2001), Inquérito à ocupação do tempo: Principais resultados, Lisboa, Instituto Nacional de Estatística.

Macedo, Eunice; Vasconcelos, Lurdes; Evans, Manuela; Lacerda, Manuela; Vaz Pinto, Margarida (2001), Revisitando Paulo Freire. Sentidos na educação, Porto, Edições ASA. 
Mikula, Gerold (1998), "Justice in the family: Multiple perspectives in the division of labor: Introduction", Social Justice Research 11(3), 211-213.

Monteiro, Rosa (2010), A Emergência do Feminismo de Estado em Portugal: uma história da criação da Comissão da Condição Feminina, Lisboa, Comissão para a Cidadania e Igualdade de Género.

Monteiro, Rosa (2014), «A conciliação trabalho-família e os riscos psicossociais», in Hernâni Veloso Neto; João Areosa; Pedro Arezes (Eds.), Manual sobre Riscos Psicossociais no Trabalho, Vila de Conde, Coleção RICOT, Civeri Publishing, 131-151.

Monteiro, Rosa; Portugal, Ślvia (2013), «As políticas de conciliação nos planos nacionais para a igualdade: uma análise dos quadros interpretativos», ex æquo 27, 97-111.

Müller, Ursula (1998), «The micropolitics of gender differences in family life», in Virgínia Ferreira; Teresa Tavares; Silvia Portugal (Eds.), Shifting bonds, shifting bounds, Oeiras, Celta Editora, 329-344.

Múrias, Cláudia; Freire, Sara (2013), «Experiências de conciliação: conversas entre ruralidade e cultura organizacional», in Hernâni Veloso Neto; João Areosa; Pedro Arezes (Eds.), Proceedings CICOT 2013, Working Conditions International Congress, Vila de Conde, Coleção RICOT, Civeri Publishing, 11-16.

Múrias, Cláudia; Freire, Sara (2014), Caminhos de Igualdade, Viana do Castelo, Associação Juvenil de Deão.

Múrias, Cláudia; Ribeiro, Raquel (2012), «Ideias a desconstruir ou a reinventar: Questionando percursos tradicionais de liderança de mulheres e de homens», in Cláudia Múrias; Marijke de Koning (Coords.), Lideranças partilhadas: Percursos de literacia para a igualdade de género e qualidade de vida, Porto, Fundação Cuidar O Futuro \& Livpsic, 201-222.

Pereirinha, José António (Coord.) (2008), Impacto e determinantes da pobreza no Feminino, Lisboa, Comissão para a Cidadania e Igualdade de Género.

Perista, Heloísa (2002), «Género e trabalho não pago: os tempos das mulheres e os tempos dos homens», Análise Social 163, 447-474.

Perista, Heloísa (Coord.) (1999), Os usos do tempo e o valor do trabalho: Uma questão de género, Lisboa, Departamento de Estudos Prospetiva e Plameamento: Centro de Informação e Documentação Económica e Social.

Poeschl, Gabrielle (2000), «Trabalho doméstico e poder familiar: Práticas, normas e ideais», Análise Social 156, 695-719.

Poeschl, Gabrielle (2010), «Desigualdades na divisão do trabalho familiar, sentimento de justiça e processos de comparação social», Análise Psicológica 38(1), 29-42.

Poeschl, Gabrielle; Múrias, Cláudia; Costa, Eleonora; Silva, Aurora (2001/2), «Representações das tarefas familiares», Cadernos de Consulta Psicológica 17/18, 161-170.

Poeschl, Gabrielle; Múrias, Cláudia; Ribeiro, Raquel (2003), «As diferenças entre os sexos: mito ou realidade?», Análise Psicológica XXI(2), 213-228.

Poeschl, Gabrielle; Pinto, Isabel; Múrias, Cláudia; Silva, Aurora; Ribeiro, Raquel (2006), «Representations of family practices, belief in sex differences and sexismo», Sex Roles 55, 111-121.

Poeschl, Gabrielle; Serôdio, Rui (1998), «Rôles de genre, travail familial: Représentations et relations», Revue Internationale de l'Educátion Familiale 2(2), 5-23.

Pordata, Base de Dados Portugal Contemporâneo, Municípios, População Desempregada segundo os Censos, [em linha] disponível em http://www.pordata.pt/Municipios/ Popula\%C3\%A7\%C3\%A3o+desempregada+segundo+os+Censos+total+e+por+sexo -162-727 [consultado em 14/10/2015].

Pordata, Base de Dados Portugal Contemporâneo, Municípios, Taxa de Emprego segundo os 
Censos, [em linha] disponível em http://www.pordata.pt/Municipios/Taxa+de+ emprego+segundo+os+Censos+total+e+por+sexo+(percentagem)-406-1994 [consultado em 14/10/2015].

Portugal, Sílvia (2008), As mulheres e a produção de bem-estar em Portugal, Oficina do CES, 319.

Rodrigues, Eduardo; Barroso, Margarida; Caetano, Ana (2010), Trabalho, família e bem-estar: factores e padrões de qualidade de vida na Europa, Lisboa, Centro de Investigação e Estudos de Sociologia - ISCTE.

Rodrigues, Julieta Almeida (1995), Continuidade e mudança nos papéis das mulheres portuguesas urbanas. O aparecimento de novas estruturas familiares, Lisboa, Comissão para a Igualdade e para os Direitos das Mulheres.

Santos, Boaventura de Sousa (1995), «Sociedade-Providência ou Autoritarismo Social?», Revista Crítica de Ciências Sociais 42, i-vii.

Santos, Boaventura de Sousa (1994), Pela mão de Alice. O social e o político na pós-modernidade, Porto, Edições Afrontamento.

Santos, Boaventura de Sousa (1993), «O Estado, as relações salariais e o bem-estar social na semi-periferia: o caso português», in Boaventura de Sousa Santos (org.), Portugal: um retrato singular, Porto, Edições Afrontamento, 17-56.

Saraceno, Chiara (1992), Sociologia da família, Lisboa, Editorial Estampa.

Vandelac, Louise (1983), Production domestique - Document $n^{-}$6: Le partage des tâches domestiques, Gouvernement du Québec, Conseil du Statut de la Femme, Bibliothèque Nationale du Québec.

Wall, Karin (2007), "Atitudes face à divisão familiar do trabalho em Portugal e na Europa», in Karin Wall; Lígia Amâncio (Orgs.), Família e género em Portugal e na Europa, Lisboa, Instituto de Ciências Sociais, 211-259.

Wall, Karin; Aboim, Sofia; Cunha, Vanessa (Eds.) (2010), A Vida Familiar no Masculino: Negociando Velhas e Novas Masculinidades, Lisboa, Comissão para a Igualdade no Trabalho e no Emprego.

Wille, Diane E. (1995), «The 1990s: Gender differences in parenting roles», Sex Roles Vol. 33, $11 / 12,803-817$.

Cláudia Múrias. Psicóloga social, formadora e consultora para a igualdade. Integrou vários projetos de investigação, formação e intervenção local. Licenciada em Psicologia e Mestre em Psicologia Social pela Faculdade de Psicologia e de Ciências da Educação da Universidade do Porto (FPCEUP), pós-graduada em Criminologia pela Faculdade de Direito da Universidade do Porto. Doutoranda na FPCEUP. Vice-presidente da Associação Espaços, Projetos Alternativos de Mulheres e Homens.

c murias@hotmail.com

Associação Espaços, Projetos Alternativos de Mulheres e Homens, Rua da Alegria 299, 4000-099 Porto, Portugal

Artigo recebido em 21 de julho de 2015 e aceite para publicação em 15 de outubro de 2015. 